\title{
Lethal olivopontoneocerebellar hypoplasia with dysmorphic features in sibs
}

\author{
I D Young, P A McKeever, M V Squier, J Grant
}

\begin{abstract}
This report describes the clinical and neuropathological features in male and female sibs who died shortly after birth as a result of frequent convulsions and lack of spontaneous respiratory effect. Both sibs had a prominent occiput with mild contractures and the female also had overlapping fingers and rockerbottom feet. The genetic and neuropathological findings were consistent with a diagnosis of an autosomal recessive form of olivopontoneocerebellar hypoplasia/ atrophy.
\end{abstract}

( $($ Med Genet 1992;29:733-5)

\section{Department of}

Clinical Genetics, City

Hospital, Hucknall

Road, Nottingham

NG5 1 PB.

I D Young

Department of

Royal Infirmary,

Leicester.

P A McKeever

Department of

Neuropathology,

Radcliffe Infirmary,

Oxford.

M V Squier

Department of Child

Health, Leicester

Royal Infirmary,

Leicester.

J Grant

Correspondence to

Dr Young.

Received 31 January 1992.

Revised version accepted

30th March 1992.

Hypoplasia of the cerebellar hemispheres in association with undervelopment of the pons ('pontoneocerebellar hypoplasia') was described in 1958 by Norman and Urich in two unrelated children, both of whom died during the first year of life. The parents of one of these children were second cousins, an observation suggestive of autosomal recessive inheritance. Recessive inheritance was also proposed as the probable mode of inheritance in male and female sibs who died in early childhood with a diagnosis of congenital 'olivopontocerebellar' atrophy, ${ }^{2}$ and in seven cases described in five Dutch families. ${ }^{3}$ We have recently encountered a further sibship in which two babies died shortly after birth with a particularly fulminant form of familial olivopontoneocerebellar hypoplasia. One of these infants also had a number of dysmorphic features.

\section{Case reports}

The affected sibs were the products of the first
Pathology, Leicester

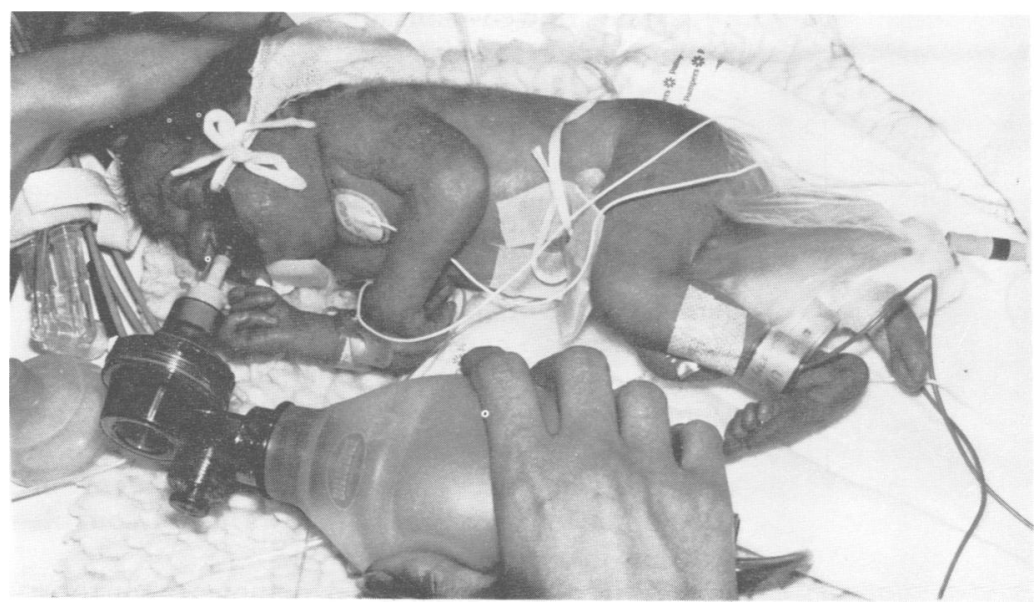

Figure 1 Case 1 shortly after birth. Note the overlapping 'trisomy 18' fingers and rockerbottom feet. two pregnancies of young, healthy, unrelated, Caucasian parents who had no history of relevant hereditary disease.

CASE 1

Concern first arose at 34 weeks' gestation when the mother noticed a reduction in fetal movements which coincided with the onset of polyhydramnios. Two weeks later after spontaneous onset of labour, she delivered a female infant weighing $1490 \mathrm{~g}$ ( $<3$ rd centile). Body length was $39.5 \mathrm{~cm}$ ( $<3 \mathrm{rd}$ centile), and head circumference $27 \cdot 2 \mathrm{~cm}$ ( $\ll 3 \mathrm{rd}$ centile). The baby made no attempt to breathe spontaneously, had frequent convulsions, and died at the age of 24 hours.

Abnormalities noted during life included a prominent occiput, micrognathia, and contractures of all four limbs with overlapping clenched fingers and bilateral rockerbottom feet (fig 1). At necropsy the total brain weight was $140 \mathrm{~g}$ (expected weight $=$ approximately $350 \mathrm{~g}$ ), and in particular the hind brain was disproportionately small weighing only $2 \mathrm{~g}$ (expected weigh $=20 \mathrm{~g}$ ) (fig 2). The lungs were in proportion to the body size and no visceral abnormalities were present. Chromosome studies using cultured lymphocytes showed a normal female karyotype.

\section{CASE 2}

This pregnancy was monitored regularly using ultrasonography from 16 weeks onwards. No abnormalities were noted until 34 weeks' gestation, when, as in the first pregnancy, polyhydramnios developed in association with a reduction in fetal movement. At 36 weeks an intrauterine convulsion was observed. At delivery three days later the male infant weighed $2010 \mathrm{~g}$ ( 3 rd centile), length $46 \mathrm{~cm}$ (50th centile), and head circumference $29.5 \mathrm{~cm}$ (3rd centile). Once again the baby made no spontaneous respiratory effort, showed frequent convulsive activity, and died at the age of 48 hours.

Dysmorphic features were less apparent in this baby than in his affected sister (case 1), and consisted of mild contractures in all limbs with a prominent occiput, receding forehead, and micrognathia (fig 3). A CT scan showed cerebellar hypoplasia with cerebral atrophy. These findings were confirmed at necropsy. Total brain weight was $104 \mathrm{~g}$ (expected for gestational age $=366 \mathrm{~g}$ ) and the hindbrain again was disproportionately small at $2.8 \mathrm{~g}$ (expected weight $=21 \mathrm{~g}$ ). No other abnormalities were detected on internal examination. 


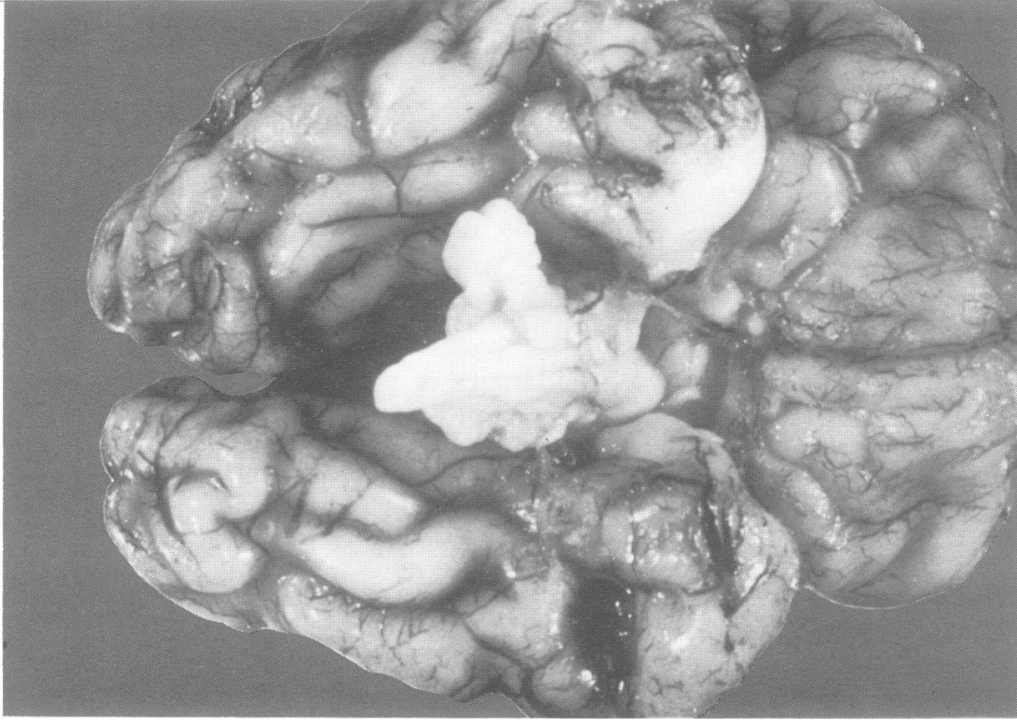

Figure 2 The brain of case 1 showing marked hypoplasia of both cerebellar hemispheres. the archi- and paleocerebellum) were well preserved. The dentate nuclei retained their normal outline but showed severe neuronal loss and reactive gliosis.

Sections of the cerebral hemispheres showed no evidence of malformation. The cortex was normally laminated. Neuronal necroses were seen in the hippocampus and subiculum and there was gliosis and macrophage infiltration in cerebral white matter, consistent with recent ischaemia or hypoxia.

The spinal cord showed normal anterior horn cells with normal and symmetrical anterior and posterior nerve roots.

\section{Discussion}

The clinical features shared by these sibs included relative microcephaly, prominent occiput, micrognathia, and contractures. In addition, case 1 had overlapping fingers and rockerbottom feet which initially suggested a possible diagnosis of trisomy 18. Neurologically their disease ran an almost identical course marked by reduction in fetal movement and polyhydramnios, presumably a manifestation of impaired deglutition, from 34 weeks onwards, with subsequent convulsions and failure to develop spontaneous respiration at birth. At necropsy both had severe cerebellar hypoplasia and neuropathological studies showed olivopontoneocerebellar hypoplasia.

The initial diagnosis of trisomy 18 in case 1 was rapidly refuted by the discovery of a normal karyotype. Alternative diagnoses which were considered included the PenaShokeir and Bowen-Conradi syndromes. The Pena-Shokeir syndrome is generally accepted as being extremely heterogeneous, representing the phenotype resulting from long standing fetal akinesia. ${ }^{4}$ Cerebellar hypoplasia has been noted in a small proportion of published cases $^{5}$ although reduction in anterior horn cells is a more characteristic finding. The absence of pulmonary hypoplasia in the cases now described is consistent with the relatively late onset of reduction in fetal movements ( 34 weeks), and together these observations suggest that the disease in these infants should not be categorised as falling within the spectrum of the Pena-Shokeir phenotype.

The Bowen-Conradi syndrome is a rare autosomal recessive disorder described mainly in the Hutterites. ${ }^{6}$ The major features are intrauterine growth retardation, microcephaly, micrognathia, contractures, rockerbottom feet, and death in early infancy. The facial profile of children with this condition is very similar to that in case 2 and cerebellar abnormalities consisting of partial agenesis and 'hypoplasia or atrophy' have been noted. ${ }^{6}$ Although this condition is regarded as lethal, the degree of neurological dysfunction is not as severe as in the cases now reported with the most noticeable differences being the achievement of spontaneous respiration and rarity of convulsions in the neonatal period.

The neuropathological demonstration of a small brainstem with hypoplasia of the cerebellar hemispheres suggests that the disorder
Figure 3 Postmortem view of case 2. Note the pointed occiput. 
in these sibs is best classified as a form of olivopontoneocerebellar hypoplasia or atrophy. In 1986, Kawagoe and $\mathrm{Jacob}^{7}$ reported almost identical neuropathological findings in a female infant who died at the age of 9 days having had generalised convulsions and 'long term apnoea attacks'. The child also had bilateral talipes. These authors proposed that the cerebellar hypoplasia was the primary abnormality and that the absence of nerve cells in the pons and inferior olives was secondary to neuronal deprivation or inactivity. A further case report by Pitella and Nogueira ${ }^{8}$ described a 9 day old male infant with widely separated nipples, overlapping toes, and hypertrichosis of the gluteal and sacrococcygeal regions with pontoneocerebellar hypoplasia. These authors suggested that the severe neuronal loss and gliosis in the pontine nuclei may represent the primary lesion which is followed by neocerebellar degeneration. Barth et $a l^{3}$ reported similar CNS findings in seven children, two boys and five girls, from a Dutch genetic isolate, four of whom died in childhood. Their illness was characterised by congenital and occasionally progressive microcephaly, myoclonic jerks, generalised convulsions, and profound developmental delay. The neuropathological findings in the case examined by Barth $e t a l^{3}$ were similar to those in our own cases.

Pontoneocerebellar hypoplasia is a term applied to a group of conditions with a variety of clinical presentations and of heterogeneous neuropathology. In our cases, severe neuronal loss and gliosis in the pontine nuclei, dentate nuclei, inferior olivary nuclei, and neocerebellum suggest a degenerative process occurring after these structures had developed, that is, atrophy rather than primary hypoplasia. The clinical history of reduced fetal movements at 34 weeks of gestation is consistent with relatively late onset of the disorder. The aetiology is diverse and the condition has been associated with both metabolic disease ${ }^{2}$ and anticonvulsant ingestion during pregnancy. ${ }^{910}$ These cases confirm that this appearance may also be the consequence of an autosomal recessive neurodegenerative process.

\section{Note added in proof}

A third pregnancy was complicated by polyhydramnios at 32 weeks. A fetal scan showed growth retardation and fixed flexion of one wrist and hand. A male infant was delivered at 38 weeks, birth weight $2760 \mathrm{~g}$, with microcephaly and fixed flexion contractures of the limbs. The heart rate was $40 /$ minute and there were no spontaneous respirations. Resuscitation was not attempted and the infant died aged 10 minutes.

The authors are grateful to Dr U M MacFadyen for referring the family.

1 Norman RM, Urich H. Cerebellar hypoplasia associated with systemic degeneration in early life. $\boldsymbol{Y}$ Neurol Neurosurg Psychiatry 1958;21:159-66.

2 Harding BN, Dunger DB, Grant DB, Erdohazi M. Familial olivopontocerebellar atrophy with neonatal onset: a recessively inherited syndrome with systemic and biochemical abnormalities. 7 Neurol Neurosurg Psychiatry 1988;51:385-90.

3 Barth PG, Vrensen GFJM, Uylings HBM, Oorthuys JWE, Stam FC. Inherited syndrome of microcephaly, dyskinesia and pontocerebellar hypoplasia: a systemic atrophy with early onset. $\mathcal{F}$ Neurol Sci 1990;97:25-42.

4 Hall JG. Invited editorial comment: analysis of Pena Shokeir phenotype. Am $\mathcal{J}$ Med Genet 1986;25:99-117.

5 Lindhout D, Hageman G, Beemer FA, Ippel PF, BreslauSiderius L, Willemse J. The Pena-Shokeir syndrome:
Silaut Siderius L, Willemse J. The Pena-Shokeir syndrome:
report of nine Dutch cases. Am $\mathcal{f}$ Med Genet 1985;21:65568 .

6 Hunter AGW, Woerner SJ, Montalvo-Hicks LDC, et al. The Bowen-Conradi syndrome - a highly lethal autosomal recessive syndrome of microcephaly, micrognathia, low birth weight and joint deformities. Am $\mathcal{F}$ Med Genet 1979;3:269-79.

7 Kawagoe T, Jacob H. Neocerebellar hypoplasia with systemic combined olivo-ponto-dentatal degeneration in a 9day-old baby: contribution to the problem of relations between malformation and systemic degeneration in early life. Clin Neuropathol 1986;5:203-8.

8 Pitella JEH, Nogueira AMMF. Pontoneocerebellar hypoplasia: report of a case in a newborn and review of the plasia: report of a case in a newborn and

9 Gadisseaux JF, Rodriguez J, Lyon J. Pontoneocerebellar hypoplasia - a probable consequence of prenatal destruction of the pontine nuclei and a possible role of phenytoin tion of the pontine nuclei and a possible role of

10 Squier W, Hope PL, Lindenbaum RH. Neocerebellar hypoplasia in a neonate following intra-uterine exposure to anticonvulsants. Dev Med Child Neurol 1990;32:72542. 